\title{
Competitividade Relativa entre Cultivares de ARROZ IRrigado e BIÓTIPO DE CAPIM-ARROZ (Echinochloa spp.) ${ }^{1}$
}

\author{
Relative Competitivity between Flooded Rice Cultivars and Echinochloa spp. \\ AGOSTINETTO, D. ${ }^{2}$, GALON, L. ${ }^{3}$, MORAES, P.V.D. ${ }^{3}$, RIGOLI, R.P. ${ }^{4}$, TIRONI, S.P. ${ }^{5}$ e \\ PANOZZO, L.E. ${ }^{6}$
}

\begin{abstract}
RESUMO - As espécies pertencentes ao gênero Echinochloa se destacam como principais infestantes das lavouras de arroz irrigado do Rio Grande do Sul, causando dano econômico à cultura devido à elevada competitividade pelos recursos do ambiente. O trabalho teve por objetivo comparar as habilidades competitivas relativas entre dois cultivares de arroz e um biótipo de capim-arroz. Para isso, foram realizados experimentos em casa de vegetação na estação de crescimento 2006/07, em delineamento experimental inteiramente casualizado, com quatro repetições. Os tratamentos foram arranjados em série substitutiva, com cinco proporções de plantas de arroz e do competidor (100:0; 75:25; 50:50; 25:75; e 0:100), mantendo a população constante de 24 plantas vaso ${ }^{-1}$ das espécies associadas. $\mathrm{O}$ arroz foi representado pelos cultivares IRGA 417 ou BR-IRGA 410, e o competidor, pelo biótipo de capim-arroz. A análise da competitividade foi efetuada por meio de diagramas aplicados a experimentos substitutivos e através de indices de competitividade relativa. As variáveis estudadas foram área foliar e massa seca aérea das plantas. Os resultados mostram que houve competição entre os cultivares de arroz IRGA 417 ou BR-IRGA 410 com o capim-arroz, independentemente da proporção de plantas na associação, com redução na área foliar e massa seca da parte aérea dos competidores. O capim-arroz apresenta menor perda de produtividade relativa, reduz as variáveis morfológicas do arroz e demonstra possuir superioridade competitiva, comparativamente aos cultivares de arroz.
\end{abstract}

Palavras-chave: Oryza sativa, interferência, competição, plantas daninhas, características morfofisiológicas.

\begin{abstract}
The Echinochloa species are among the most important weeds in flooded rice fields of Rio Grande do Sul, causing economic losses to the culture, due to its high competivity for environmental resources. The objective of this study was to compare the relative competitive abilities between two rice cultivars and an Echinochloa spp. biotype. Greenhouse experiments were conducted in 2006/07 growing season utilizing a completely randomized design with four replications. The treatments were arranged in a replacement series experiment by establishing five proportions of rice plants and competitor (100:0; 75:25; 50:50; 25:75 and 0:100), maintaining a constant population of 24 plants per pot. Rice cultivars were IRGA 417 or BR-IRGA 410, and the competitor was an Echinochloa spp. biotype. Competitive analysis was accomplished through diagrams usually applied to replacement series studies and indexes of relative competivity. The plant variables evaluated were: leaf area and shoot dry weight. There was competition between the IRGA 417or BR-IRGA 410 cultivars and the Echinochloa spp., independently of the proportion of the plants, with the competitors presenting reduced leaf area and shoot dry matter weight. Echinochloa spp. presents smaller relative productivity loss, reduces the morphological rice variables, and shows to be more competitive than the rice cultivars.
\end{abstract}

Keywords: Oryza sativa, interference, competition, weeds, morphophysiological characteristics.

Recebido para publicação em 5.2.2008 e na forma revisada em 17.7.2008.

2 Engo-Agr ${ }^{\circ}$, Dr., Professor do Dep. de Fitossanidade da Faculdade de Agronomia Eliseu Maciel da Universidade Federal de Pelotas, Bolsista do CNPq; ${ }^{3}$ Eng $^{0}-A g r o$, aluno do Programa de Pós-Graduação em Fitossanidade da UFPel, Caixa postal 354 , 96010-900, Capão do Leão-RS - Bolsista CAPES, <galonleandro@ig.com.br > (autor para correspondência); ${ }^{4}$ Bióloga, aluna do Programa de Pós-Graduação em Fitossanidade da UFPel; ${ }^{5}$ Aluno de Graduação da Faculdade de Agronomia Eliseu Maciel UFPel; ${ }^{6}$ Engo-Agrọ , aluno do Programa de Pós-Graduação em Fitossanidade da UFPel. 


\section{INTRODUÇÃO}

A cultura do arroz destaca-se como uma das mais importantes do mundo; por apresentar facilidade de adaptação a condições edafoclimáticas distintas, é cultivada nos mais diversos ambientes em todos os continentes (Ruiz-Santella et al., 2003). No Brasil, encontra-se amplamente difundida em praticamente todos os Estados da Federação; contudo, é no Rio Grande do Sul e Santa Catarina que a cultura aparece em grandes extensões, ocupando área superior a um milhão de hectares, e também onde se obtêm as maiores produtividades de grãos, quando comparadas às demais regiões produtoras do cereal do País (CONAB, 2008). Todavia, sabe-se que o potencial de produtividade da cultura ainda pode ser melhorado. Dentre os fatores que contribuem para isso, destaca-se a competição com as plantas daninhas, cuja ausência de controle pode ocasionar perdas de produtividade de grãos de aproximadamente $85 \%$ em situações de ausência de controle (Fleck et al., 2004).

As plantas podem competir entre si (competição intra-específica) e com outras espécies (competição interespecífica) pelos recursos luz, água, nutrientes e, em algumas situações, também por $\mathrm{CO}_{2}$. A duração da competição determina prejuízos variáveis no crescimento e no desenvolvimento e, conseqüentemente, na produção das culturas (Christoffoleti \& Victória Filho, 1996; Lamego et al., 2004; Fleck et al., 2008). Para que ocorra competição, há necessidade de sobreposição suficiente dos nichos dos indivíduos que competem entre si, de modo que eles passem a utilizar os mesmos recursos (Maluf, 1999).

Entre as plantas daninhas presentes nas lavouras orizicolas, destaca-se o capim-arroz (Echinochloa spp.), o qual apresenta semelhanças morfofisiológicas com as plantas de arroz, com vasta distribuição nas lavouras cultivadas e altos níveis de infestação (Andres et al., 2007a). As perdas de produtividade das culturas, em decorrência da competição de plantas daninhas, geralmente aumentam quanto mais semelhantes forem suas características morfofisiológicas (Lamego et al., 2004). A principal forma de interferência que se estabelece entre o capim-arroz e o arroz irrigado é a competição pelos recursos luz e nutrientes. A competição do capim-arroz com a cultura afeta negativamente a quantidade e a qualidade da produção, bem como a eficiência de aproveitamento dos recursos do ambiente; elevadas infestações da planta daninha podem causar reduções de até $90 \%$ na produtividade de grãos da cultura (Melo et al., 2006). Infestações de uma planta de capim-arroz $\mathrm{m}^{-2}$ podem ocasionar perdas de produtividade de grãos variável de 5 a $30 \%$, em função do cultivar semeado e da época de entrada de água na lavoura (Galon et al., 2007a; Agostinetto et al., 2007), o que influencia o manejo que será adotado com a cultura do arroz irrigado, em relação à população de capim-arroz presente na lavoura (Galon et al., 2007b; Andres et al., 2007b).

Estudos sobre competitividade de culturas com plantas daninhas permitem desenvolver estratégias para seu manejo. Recentemente, pesquisas foram intensificadas e direcionadas a definir características que confiram maior habilidade competitiva, principalmente nas culturas de arroz e trigo e, em menor proporção, de milho e soja (Fleck, et al., 2006, 2008; Rigoli et al., 2008). A habilidade competitiva se caracteriza pela dominância de um indivíduo sobre seus vizinhos, os quais utilizam, simultaneamente, um mesmo recurso com limitada disponibilidade (Aarssen, 1983). A habilidade competitiva pode ser analisada, quanto aos efeitos, sob dois aspectos: supressão do crescimento de vizinhos e tolerância à presença de vizinhos (Goldberg \& Landa, 1991). O grau de competição depende de fatores relacionados à comunidade infestante (espécie, população, distribuição e época de emergência) e à própria cultura (espécie ou cultivar, espaçamento entre linhas e população). Dentre os fatores ligados à comunidade infestante, a população de plantas pode ser considerada um dos mais importantes, de forma que, quanto maior a população da comunidade infestante, maior será a quantidade de indivíduos que disputam os mesmos recursos do ambiente e mais intensa será a competição sofrida pela cultura (Christoffoleti \& Victória Filho, 1996).

Em nivel de lavoura, a população das plantas cultivadas geralmente é constante, ao passo que a população das plantas daninhas varia de acordo com a quantidade de sementes depositadas no banco do solo e as condições ambientais que alteram o nivel de infestação. 
Desse modo, nos estudos de competição, não basta avaliar somente a população de plantas no processo competitivo, mas também é importante verificar a influência da variação na proporção entre as espécies (Christoffoleti \& Victória Filho, 1996).

A determinação das interações competitivas entre genótipos e espécies de plantas requer delineamentos experimentais e métodos de análise apropriados, sendo os experimentos substitutivos convencionais os mais usados para esclarecer tais relações (Roush et al., 1989). A interpretação dos dados de experimento substitutivo resulta em medida da competitividade entre as espécies, com base na resposta relativa da variável em estudo, podendo ser: a produção de massa seca da parte aérea, área foliar, estatura, afilhamento e índice de cobertura do solo; contudo, a resposta é dada pela variação da proporção de plantas associadas (Crotser \& Witt, 2000; Estorninos Jr. et al., 2002; Cralle et al., 2003; Vida et al., 2006). Em experimentos conduzidos em séries substitutivas, geralmente as culturas demonstram maior habilidade competitiva do que as espécies daninhas; isso ocorre porque, em campo, o efeito da planta daninha sobre a cultura se deve, principalmente, ao nível de infestação e não à sua habilidade competitiva individual (Vilá et al., 2004). No entanto, quando há competição entre indivíduos do mesmo gênero e/ou espécie, a vantagem competitiva da cultura poderá ser alterada, uma vez que ambos exploram o mesmo nicho ecológico. Assim, experimentos conduzidos em série de substituição entre cultivares de arroz e de capimarroz podem refletir a capacidade competitiva das espécies em função da variação populacional, já que em campo as plantas daninhas apresentam maior habilidade competitiva do que as culturas, em razão da maior densidade de plantas por área, enquanto nas culturas a densidade é fixa.

O objetivo deste trabalho foi comparar habilidades competitivas dos cultivares de arroz IRGA 417 ou BR-IRGA 410 em relação ao biótipo de capim-arroz através de experimentos do tipo série de substituição.

\section{MATERIAL E MÉTODOS}

Experimentos foram conduzidos em casa de vegetação da Faculdade de Agronomia
Eliseu Maciel (FAEM) da Universidade Federal de Pelotas (UFPel), Município do Capão do Leão RS, na estação de cultivo 2006/07. Os ensaios foram alocados em vasos plásticos com capacidade volumétrica de oito litros, preenchidos com solo oriundo de lavoura orizícola, classificado como Planossolo Hidromórfico Eutrófico solódico, pertencente à unidade de mapeamento Pelotas (Embrapa, 1999). A correção da fertilidade do solo foi realizada conforme as recomendações para a cultura do arroz irrigado (SOSBAI, 2005). O delineamento experimental foi o completamente casualizado, com quatro repetições. Os competidores testados incluíram os cultivares de arroz IRGA 417 ou BRIRGA 410 e um biótipo de capim-arroz (Echinochloa spp.).

Primeiramente, foi realizado um experimento preliminar tanto para a cultura do arroz quanto para o capim-arroz, em sistema de monocultivo, com o objetivo de determinar a população de plantas em que a produção final se torna constante. Neste, utilizaram-se populações de 1, 2, 4, 8, 16, 24, 32, 40, 48, 56 e 64 plantas vaso $^{-1}$ (equivalentes a $25,49,98,196$, $392,587,784,980,1.176,1.372$ e 1.568 plantas $\mathrm{m}^{-2}$, respectivamente). A produção final constante foi obtida com população de 24 plantas vaso $^{-1}$, o que equivaleu a 587 plantas $\mathrm{m}^{-2}$ (dados não apresentados).

Outros dois experimentos foram instalados para avaliar a competitividade das variedades de arroz IRGA 417 e BR-IRGA 410 com plantas de capim-arroz, ambos conduzidos em série de substituição, nas diferentes combinações dos cultivares e do biótipo de capim-arroz, variando-se as proporções relativas de plantas vaso ${ }^{-1}$ $(24: 0 ; 18: 6 ; 12: 12 ; 6: 18 ; 0: 24)$, mantendo-se constante a população total de plantas (24 plantas vaso ${ }^{-1}$ ). Para estabelecer as populações desejadas em cada tratamento e obter uniformidade das plântulas, as sementes foram previamente semeadas em bandejas, sendo posteriormente transplantadas para os vasos.

Na primeira combinação de competidores, testaram-se os cultivares de arroz IRGA 417 ou BR-IRGA 410 com o biótipo de capim-arroz. Aos 50 dias após a emergência (DAE), avaliaram-se as variáveis área foliar (AF) e massa seca da parte aérea das plantas (MSPA), separando-se a cultura e a planta daninha. A quantificação da $\mathrm{AF}$ foi realizada com auxílio de 
integrador eletrônico, em todas as plantas presentes nos vasos. Para se obter a MSPA, todas as plantas foram seccionadas ao nível do solo e a secagem do material foi efetuada em estufa de circulação forçada de ar, aquecida a $60{ }^{\circ} \mathrm{C}$, até se obter massa constante.

Os dados foram analisados através do método da análise gráfica da variação ou produtividade relativa (Radosevich, 1987; Roush et al., 1989; Cousens, 1991; Bianchi et al., 2006). O referido procedimento, também conhecido como método convencional para experimentos substitutivos, consiste na construção de um diagrama tendo por base as produtividades ou variações relativas (PR) e total (PRT). Quando o resultado da PR for uma linha reta, significa que as habilidades das espécies são equivalentes. Caso a PR resulte em linha côncava, indica que existe prejuízo no crescimento de uma ou de ambas as espécies. Ao contrário, se a PR mostrar linha convexa, há beneficio no crescimento de uma ou de ambas as espécies. Quando a PRT for igual à unidade (1) (linha reta), ocorre competição pelos mesmos recursos; se ela for superior a 1 (linha convexa), a competição é evitada. Caso a PRT seja menor que 1 (linha côncava), ocorre prejuízo mútuo ao crescimento (Cousens, 1991).

Foram calculados os indices de competitividade relativa $(\mathrm{CR})$, coeficiente de agrupamento relativo (K) e agressividade (A). A CR representa o crescimento comparativo da espécie $\mathrm{X}$ em relação a Y; $\mathrm{K}$ indica a dominância relativa de uma espécie sobre a outra; e A aponta qual das espécies é mais agressiva. Assim, os indices CR, K e A indicam qual espécie se manifesta mais competitiva, e sua interpretação conjunta indica com maior segurança a competitividade das espécies (Cousens, 1991). A espécie $X$ é mais competitiva que $Y$ quando $\mathrm{CR}>1, \mathrm{~K}_{\mathrm{x}}>\mathrm{K}_{\mathrm{y}}$ e $\mathrm{A}>0$; por outro lado, a espécie $\mathrm{Y}$ é mais competitiva que $\mathrm{X}$ quando $\mathrm{CR}<1, \mathrm{~K}_{\mathrm{x}}<\mathrm{K}_{\mathrm{y}}$ e $\mathrm{A}<0$ (Hoffman \& Buhler, 2002). Para calcular esses indices foram usadas as proporções 50:50 das espécies ou as populações de 12:12 plantas vaso ${ }^{-1}$, utilizando-se as seguintes equações: $\mathrm{CR}=\mathrm{PR}_{\mathrm{x}} / \mathrm{PR}_{\mathrm{y}} ; \mathrm{K}_{\mathrm{x}}=\mathrm{PR}_{\mathrm{x}} /(1-$ $\left.\mathrm{PR}_{\mathrm{x}}\right) ; \mathrm{K}_{\mathrm{y}}=\mathrm{PR}_{\mathrm{y}} /\left(1-\mathrm{PR}_{\mathrm{y}}\right) ; \mathrm{A}=\mathrm{PR}_{\mathrm{x}}-\mathrm{PR}_{\mathrm{y}}$, conforme sugerido por Cousens \& O’Neill (1993).

O procedimento de análise estatística da produtividade ou variação relativa incluiu o cálculo das diferenças para os valores de PR (DPR), obtidos nas proporções 25, 50 e $75 \%$, em relação aos valores pertencentes à reta hipotética nas respectivas proporções, quais sejam: 0,25, 0,50 e 0,75 para PR (Passini, 2001; Bianchi et al., 2006). Utilizou-se o teste " $t$ " para testar as diferenças relativas aos índices DPR, PRT, CR, K e A (Roush et al., 1989; Hoffman \& Buhler, 2002). Considerou-se como hipótese nula, para testar as diferenças de DPR e A, que as médias fossem iguais a zero $\left(\mathrm{H}_{\mathrm{o}}=0\right)$; para PRT e CR, que as médias fossem iguais a um $\left(\mathrm{H}_{\mathrm{o}}=1\right)$; e, para $\mathrm{K}$, que as médias das diferenças entre $\mathrm{K}_{\mathrm{x}}$ e $\mathrm{K}_{\mathrm{y}}$ fossem iguais a zero $\left[\mathrm{H}_{\mathrm{o}}=\right.$ $\left.\left(\mathrm{K}_{\mathrm{x}}-\mathrm{K}_{\mathrm{y}}\right)=0\right]$. O critério para considerar as curvas de PR e PRT diferentes das retas hipotéticas foi que, no mínimo em duas proporções, ocorressem diferenças significativas pelo teste " $t$ " (Bianchi et al., 2006). Do mesmo modo, considerou-se, para os índices $\mathrm{CR}, \mathrm{K}$ e A, a existência de diferenças em competitividade quando, no mínimo em dois deles, houvesse diferença significativa pelo teste " $\mathrm{t}$ ".

Os resultados obtidos para AF e MSPA, expressos em valores médios por tratamento, foram submetidos à análise de variância pelo teste F; quando este foi significativo, compararam-se as médias dos tratamentos pelo teste de Dunnett, considerando-se as monoculturas como testemunhas nessas comparações. Em todas as análises estatísticas efetuadas adotou-se como probabilidade de erro $p \leq 0,05$, com a utilização do programa computacional SAS (1989).

\section{RESULTADOS E DISCUSSÃO}

A análise gráfica, para as combinações de plantas dos cultivares IRGA 417 ou BR-IRGA 410 com o biótipo de capim-arroz (competidor), demonstrou que os dois cultivares testados apresentaram semelhança na competição com a planta daninha e que ocorreram diferenças significativas para as variáveis $\mathrm{AF}$ e MSPA, em todas as proporções de plantas testadas (Figuras 1 e 2; Tabela 1). Com relação à PRT, houve diferenças entre os valores esperados e estimados para as variáveis estudadas, tendo estas apresentado valores médios inferiores a 1, em todas as combinações. A presença de linhas côncavas, em todas as simulações e variáveis estudadas, demonstrou que ocorreu 
Tabela 1 - Diferenças relativas para as variáveis área foliar e massa seca aérea dos cultivares de arroz IRGA417 ou BR-IRGA410 e de capim-arroz, aos 50 dias após a emergência. FAEM/UFPel, Capão do Leão-RS, 2006/07

\begin{tabular}{|c|c|c|c|}
\hline \multirow{2}{*}{ Variável } & \multicolumn{3}{|c|}{ Proporção de plantas associadas (arroz:competidor) } \\
\hline & $75: 25$ & $50: 50$ & $25: 75$ \\
\hline & \multicolumn{3}{|c|}{ Área foliar } \\
\hline IRGA 417 & $-0,38( \pm 0,01)^{*}$ & $-0,34( \pm 0,00)^{*}$ & $-0,21( \pm 0,00)^{*}$ \\
\hline Capim-arroz & $-0,15( \pm 0,00)^{*}$ & $-0,14( \pm 0,01)^{*}$ & $-0,09( \pm 0,03)$ \\
\hline Total & $0,47( \pm 0,01)^{*}$ & $0,52( \pm 0,01)^{*}$ & $0,70( \pm 0,03)^{*}$ \\
\hline BR-IRGA 410 & $-0,29( \pm 0,01)^{*}$ & $-0,38( \pm 0,01)^{*}$ & $-0,22( \pm 0,00)^{*}$ \\
\hline Capim-arroz & $-0,13( \pm 0,01)^{*}$ & $-0,13( \pm 0,03)^{*}$ & $0,12( \pm 0,04)$ \\
\hline \multirow[t]{2}{*}{ Total } & $0,58( \pm 0,01)^{*}$ & $0,51( \pm 0,02)^{*}$ & $0,91( \pm 0,04)$ \\
\hline & \multicolumn{3}{|c|}{ Massa seca da parte aérea } \\
\hline IRGA 417 & $-0,32( \pm 0,02)^{*}$ & $-0,33( \pm 0,01)^{*}$ & $-0,21( \pm 0,00)^{*}$ \\
\hline Capim-arroz & $-0,15( \pm 0,00)^{*}$ & $-0,10( \pm 0,01)^{*}$ & $-0,05( \pm 0,03)$ \\
\hline Total & $0,53( \pm 0,02)^{*}$ & $0,56( \pm 0,01)^{*}$ & $0,74( \pm 0,03)^{*}$ \\
\hline BR-IRGA 410 & $-0,30( \pm 0,02)^{*}$ & $-0,36( \pm 0,01)^{*}$ & $-0,21( \pm 0,00)^{*}$ \\
\hline Capim-arroz & $-0,13( \pm 0,01)^{*}$ & $-0,16( \pm 0,01)^{*}$ & $0,02( \pm 0,06)$ \\
\hline Total & $0,57( \pm 0,02)^{*}$ & $0,48( \pm 0,00)^{*}$ & $0,81( \pm 0,05)^{*}$ \\
\hline
\end{tabular}

* Diferença significativa pelo teste " $\mathrm{t}$ " $(\mathrm{p} \leq 0,05)$. Valores entre parênteses representam o erro-padrão da média.

competição pelos mesmos recursos do ambiente, havendo prejuízo mútuo ao crescimento tanto da cultura quanto do competidor (Figuras 1 e 2 ), pois, de acordo com Harper (1977), quando $\mathrm{PRT}<1$, há um antagonismo mútuo entre as espécies que estão competindo pelos recursos do ambiente.

A análise gráfica das combinações de plantas dos cultivares IRGA 417 ou BR-IRGA 410 e do biótipo de capim-arroz, para as variáveis em estudo, mostrou que os desvios observados das retas da $\mathrm{PR}$, em relação às retas esperadas, são representados por linhas côncavas para a cultura e para o competidor, demonstrando que ambos competem pelos mesmos recursos do ambiente (Figuras 1 e 2). Considerando que para haver significância pelo menos duas proporções de plantas devem diferir (Bianchi et al., 2006), verificaram-se diferenças entre as retas estimadas e esperadas para as variáveis AF e MSPA (Figuras 1 e 2; Tabela 1).

O crescimento relativo do capim-arroz, comparativamente ao dos cultivares de arroz IRGA 417 ou BR-IRGA 410, foi sempre maior quando presente na maior proporção de plantas (Figuras 1 e 2; Tabela 1). A provável causa de o capim-arroz apresentar maior crescimento naquela proporção pode estar relacionada à estatura de plantas, tornando-se mais eficiente na captura da radiação solar e impondo sombreamento à cultura (Garrity et al., 1992). Deve-se ressaltar que, em experimentos substitutivos, existe pouca evidência de haver mudanças qualitativas devido ao aumento da população, ou seja, a dominância de uma espécie sobre a outra raramente muda com a alteração da população (Cousens \& O’Neill, 1993).

Observou-se que o capim-arroz apresentou menor perda de PR comparativamente à dos cultivares, especialmente quando em maior proporção de plantas (Tabela 1). Constataramse aumentos na PRT da combinação quanto maiores foram as proporções de plantas correspondentes ao competidor - situação significativa para as ambas as variáveis estudadas. Esse comportamento mostra que as espécies são competitivas e que uma não contribui mais que o esperado para a produtividade total da outra (Radosevich, 1987). Por pertencerem à mesma familia botânica, esperava-se que os cultivares de arroz e o capim-arroz explorassem o mesmo nicho ecológico e competissem pelos mesmos recursos do ambiente, apresentando diferenças em competitividade, pois estas foram verificadas em espécies aparentadas, como, por exemplo, entre arroz $\mathrm{x}$ arrozvermelho (Pantone \& Baker, 1991; Estorninos Jr. et al., 2005) e entre sorgo x sorgo-de-alepo 

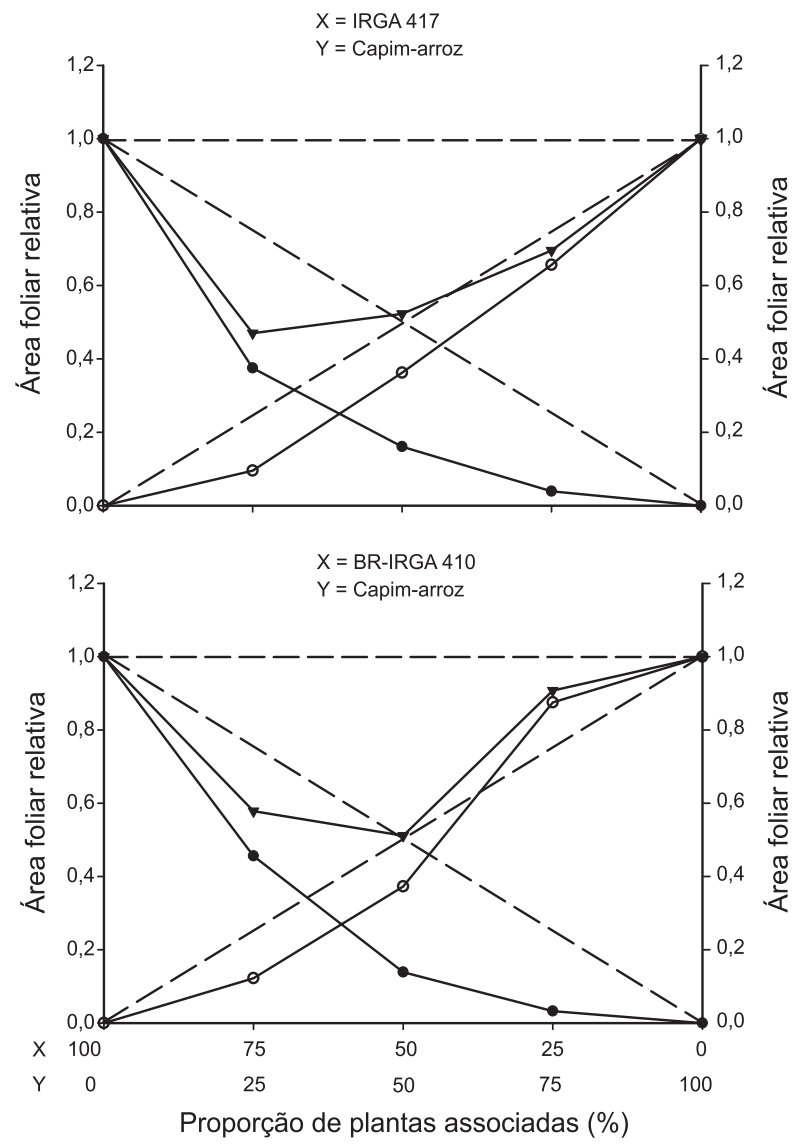

Figura 1 - Diagramas da área foliar relativa de plantas, FAEM/ UFPel, Capão do Leão-RS, 2006/07. (•) AFR do cultivar de arroz (X), ( O AFR do competidor (Y) e ( $\mathbf{\nabla})$ área foliar relativa total (AFRT).

ou entre sorgo $\mathrm{x}$ biótipos silvestres originados do sorgo cultivado (Hoffman \& Buhler, 2002).

O crescimento relativo dos cultivares IRGA 417 ou BR-IRGA 410 apresentou, de modo geral, valores semelhantes na mesma proporção de plantas em competição, para as variáveis AF e MSPA (Figuras 1 e 2; Tabelas 1 e 2). Assim, apesar de os cultivares apresentarem características diferenciadas quanto à estatura e ao ciclo de desenvolvimento (SOSBAI, 2005), não se observou diferenciação na competição dessas com o capim-arroz. Esses resultados permitem inferir que não há efeito acentuado de características intrinsecas de cultivar sobre o capim-arroz e que a habilidade daqueles em interferir sobre a planta daninha foi equivalente. Os resultados observados discordam dos encontrados por Fischer et al. (1997), Fleck et al. (2004) e Galon et al., (2007a), os
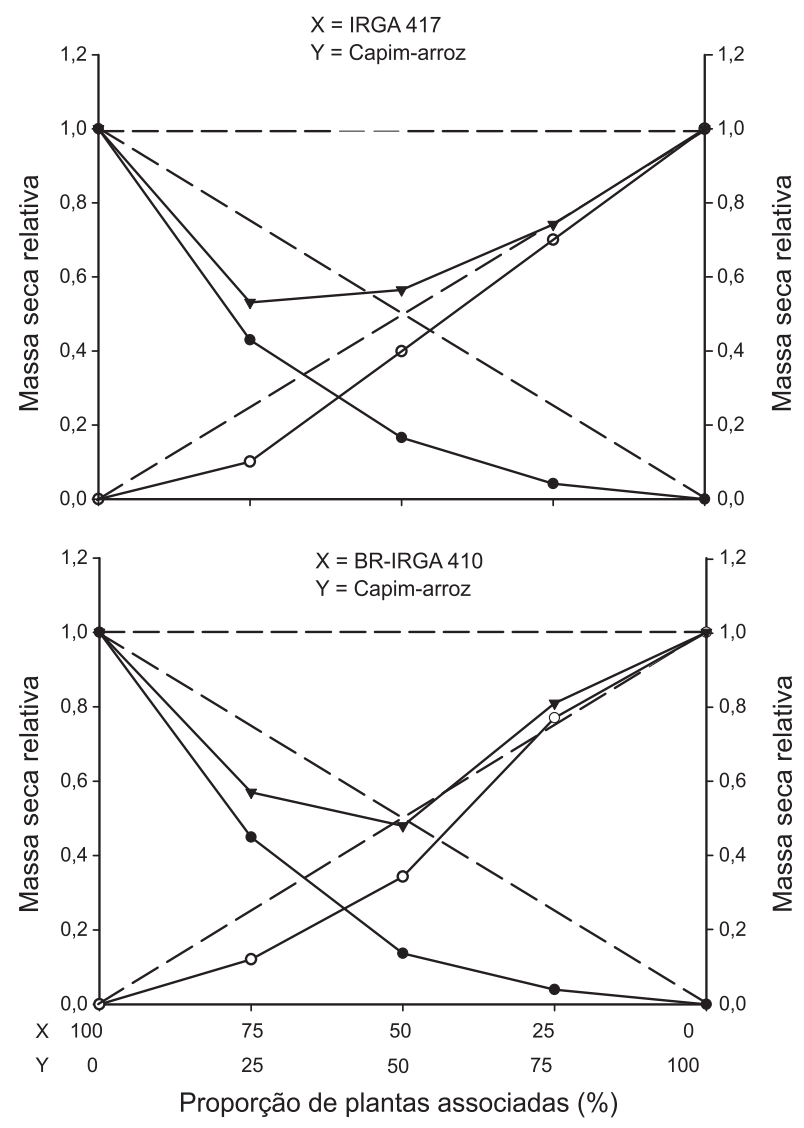

Figura 2 - Diagramas da massa seca relativa da parte aérea de plantas, FAEM/UFPel, Capão do Leão-RS, 2006/07. (•) MSR do cultivar de arroz (X), (O) MSR do competidor (Y) e ( $\mathbf{\nabla})$ massa seca relativa total (MSRT).

quais afirmaram a existência de variabilidade competitiva de acordo com o ciclo de desenvolvimento de cada cultivar. Contudo, isso pode decorrer do fato de que nos trabalhos desenvolvidos em campo tem-se a influência de fatores bióticos e abióticos e que isso pode atuar de maneira diferenciada para cada cultivar; assim, tem-se uma maior importância da variação do ciclo de desenvolvimento e da estatura de plantas, o que não se observa em casa de vegetação, em razão de o ambiente ser controlado e de haver menor pressão por parte dos fatores bióticos e abióticos.

As variáveis morfológicas AF e MSPA, dos cultivares IRGA 417 ou BR-IRGA 410, foram reduzidas quando competiram com o capimarroz em todas as associações estudadas, independentemente da proporção de plantas (Tabela 2). Quanto mais elevada a proporção 
Tabela 2 - Diferenças entre plantas associadas ou não dos cultivares de arroz IRGA 417 ou BR-IRGA 410 e de capim-arroz para as variáveis área foliar e massa seca aérea, aos 50 dias após a emergência. FAEM/UFPel, Capão do Leão-RS, 2006/07

\begin{tabular}{|c|c|c|}
\hline $\begin{array}{l}\text { Proporção de plantas } \\
\text { (Arroz:competidor) }\end{array}$ & $\begin{array}{c}\text { Área foliar } \\
\left(\mathrm{cm}^{2} \text { número de plantas tratamento }{ }^{-1}\right)\end{array}$ & $\begin{array}{c}\text { Massa seca da parte aérea } \\
\text { (g número de plantas tratamento }{ }^{-1} \text { ) }\end{array}$ \\
\hline & \multicolumn{2}{|c|}{ Cultivar IRGA 417} \\
\hline $100: 0(\mathrm{~T})$ & 6556,17 & 51,72 \\
\hline $75: 25$ & $3276,82 *$ & $29,64 *$ \\
\hline $50: 50$ & $2104,50 *$ & $17,15^{*}$ \\
\hline $25: 75$ & $1027,61^{*}$ & $8,62 *$ \\
\hline \multirow[t]{2}{*}{$\mathrm{CV}(\%)$} & 7,54 & 10,77 \\
\hline & \multicolumn{2}{|c|}{ Competidor capim-arroz } \\
\hline $0: 100(\mathrm{~T})$ & 7388,97 & 73,75 \\
\hline $25: 75$ & $6464,18^{*}$ & 68,85 \\
\hline $50: 50$ & $5353,67 *$ & $58,87^{*}$ \\
\hline $75: 25$ & $2814,52 *$ & $29,85^{*}$ \\
\hline \multirow[t]{2}{*}{ CV (\%) } & 7,11 & 7,86 \\
\hline & \multicolumn{2}{|c|}{ Cultivar BR-IRGA 410} \\
\hline 100:0 (T) & 5738,57 & 50,26 \\
\hline $75: 25$ & $3487,76^{*}$ & $30,11 *$ \\
\hline $50: 50$ & $1593,68 *$ & $13,75^{*}$ \\
\hline $25: 75$ & $749,61^{*}$ & $7,93 *$ \\
\hline \multirow[t]{2}{*}{ CV (\%) } & 11,60 & 7,59 \\
\hline & \multicolumn{2}{|c|}{ Competidor capim-arroz } \\
\hline $0: 100(\mathrm{~T})$ & 5494,61 & 70,73 \\
\hline $25: 75$ & 6409,89 & 72,63 \\
\hline $50: 50$ & $4094,79 *$ & $48,54 *$ \\
\hline $75: 25$ & $2691,57 *$ & $34,19 *$ \\
\hline $\mathrm{CV}(\%)$ & 11,32 & 10,99 \\
\hline
\end{tabular}

* Média difere da testemunha (T) pelo teste de Dunnett $(\mathrm{p}<0,05)$.

do competidor na associação com os cultivares, maiores foram os danos a variáveis da cultura do arroz. Já para o capim-arroz, em geral, verificou-se redução na AF e MSPA quando em igual ou menor proporção de plantas, comparativamente aos cultivares.

$\mathrm{O}$ cultivar de arroz $\mathrm{X}$ é mais competitivo que o capim-arroz Y, quando comparados pelos coeficientes desenvolvidos por Hoffman \& Buhler (2000): CR > 1, $\mathrm{K}_{\mathrm{x}}>\mathrm{K}_{\mathrm{y}}$ e A > 0. Assim, adotou-se como critério para comprovar superioridade competitiva a ocorrência de diferença significativa em pelo menos dois índices (Bianchi et al., 2006). O capim-arroz apresentou maior crescimento, para as variáveis avaliadas, quando em competição com os cultivares IRGA 417 ou BR-IRGA 410, conforme indicado pelo índice CR (Tabela 3). Ao utilizar os índices $\mathrm{K}$ e A, identificou-se que o capimarroz novamente mostrou-se mais competitivo que os cultivares de arroz nas duas variáveis morfológicas testadas (Tabela 3). Em todas as comparações, verificaram-se diferenças entre os cultivares de arroz e o capim-arroz, o que demonstra que ambos não se equivalem em termos de competição pelos recursos do ambiente, destacando-se o capim-arroz como mais competitivo que os cultivares. Utilizando os três indices para definir competitividade, foi verificado que o sorgo cultivado foi mais competitivo que Sorghum halepense (Hoffman \& Buhler, 2002) e que o nabo forrageiro foi mais competitivo que genótipos de soja (Bianchi et al., 2006).

Interpretando conjuntamente as análises gráficas de variáveis relativas e suas 
Tabela 3 - Índices de competitividade entre cultivares de arroz e competidor, expressos por competitividade relativa (CR), coeficientes de agrupamentos relativos $(\mathrm{K})$ e de agressividade $(\mathrm{A})$, obtidos em experimentos conduzidos em séries substitutivas. FAEM/UFPel, Capão do Leão-RS, 2006/07

\begin{tabular}{|l|c|c|c|c|}
\hline \multirow{2}{*}{ Variável } & CR & $\mathrm{K}_{\mathrm{x}}$ (arroz) & $\mathrm{K}_{\mathrm{y}}$ (competidor) & A \\
\cline { 2 - 6 } & \multicolumn{5}{|c|}{ Área foliar } \\
\hline IRGA 417 x Competidor capim-arroz & $0,44( \pm 0,02)^{*}$ & $0,19( \pm 0,004)$ & $0,57( \pm 0,03)^{*}$ & $-0,20( \pm 0,01)^{*}$ \\
\hline BR-IRGA 410 x Competidor capim-arroz & $0,39( \pm 0,06)^{*}$ & $0,16( \pm 0,01)$ & $0,60( \pm 0,07)^{*}$ & $-0,23( \pm 0,04)^{*}$ \\
\hline & \multicolumn{5}{|c|}{ Massa seca da parte aérea } \\
\hline IRGA 417 x Competidor capim-arroz & $0,42( \pm 0,03)^{*}$ & $0,20( \pm 0,01)$ & $0,67( \pm 0,03)^{*}$ & $-0,23( \pm 0,02)^{*}$ \\
\hline BR-IRGA 410 x Competidor capim-arroz & $0,40( \pm 0,03)^{*}$ & $0,16( \pm 0,008)$ & $0,52( \pm 0,02)^{*}$ & $-0,21( \pm 0,01)^{*}$ \\
\hline
\end{tabular}

* Diferença significativa pelo teste "t" ( $\mathrm{p} \leq 0,05)$. Valores entre parênteses representam o erro-padrão da média. $\mathrm{K}_{\mathrm{x}} \mathrm{e} \mathrm{K}_{\mathrm{y}}$ são os coeficientes de agrupamentos relativos do cultivar de arroz e do competidor, respectivamente.

significâncias em relação aos valores equivalentes (Figuras 1 e 2; Tabela 1), às variáveis morfológicas (Tabela 2) e aos índices de competitividade (Tabela 3), em geral, constatouse efeito da competição do capim-arroz sobre os cultivares de arroz, demonstrando que essa espécie daninha possui superioridade competitiva em relação aos cultivares. Ao explorarem basicamente o mesmo nicho ecológico, os cultivares de arroz e o capim-arroz competem pelos mesmos recursos no tempo e/ou no espaço. Assim, as diferenças em termos de competitividade das espécies estudadas podem ser devido a estas apresentarem características morfofisiológicas semelhantes. Resultados similares foram observados em trabalhos que avaliaram a competitividade entre espécies com algum grau de semelhança (Pantone \& Baker, 1991; Hoffman \& Buhler, 2002; Estorninos Jr. et al., 2005; Fleck et al., 2008; Rigoli et al., 2008). O conhecimento da dinâmica e da competitividade entre plantas - em especial, o arroz irrigado e o capim-arroz - torna-se fundamental para a tomada de decisão de controlar a planta daninha em determinada população que não irá causar interferência negativa sobre a cultura, ainda mais considerando-se que o fluxo potencial de emergência de capim-arroz por safra pode ser de até 2.400 plantas $\mathrm{m}^{-2}$ em áreas de monocultivo (Melo et al., 2004).

Os resultados obtidos permitem concluir que houve competição entre os cultivares de arroz IRGA 417 ou BR-IRGA 410 com o capimarroz, independentemente da proporção de plantas na associação, com redução na área foliar e massa seca da parte aérea dos competidores. O capim-arroz apresenta menor perda de produtividade relativa, reduz as variáveis morfológicas do arroz e demonstra possuir superioridade competitiva, comparativamente aos cultivares de arroz.

\section{AGRADECIMENTOS}

À Coordenação de Aperfeiçoamento de Pessoal de Nivel Superior (CAPES), à Fundação de Amparo à Pesquisa do Estado do Rio Grande do Sul (FAPERGS) e ao Conselho Nacional de Desenvolvimento Científico e Tecnológico (CNPqBrasil), pelo apoio financeiro e pela concessão de bolsas.

\section{LITERATURA CITADA}

AARSSEN, L. W. Ecological combining ability and competitive combining ability in plants: Toward a general evolutionary theory of coexistence in systems of competition. Am. Natur., v. 122, n. 6, p. 707-731, 1983.

AGOSTINETTO, D. et al. Interferência de capim-arroz (Echinochloa spp.) na cultura do arroz irrigado (Oryza sativa) em função da época de irrigação. Planta Daninha, v. 25, n. 4, p. 689-696, 2007.

ANDRES, A. et al. Detecção da resistência de capim-arroz (Echinochloa sp.) ao herbicida quinclorac em regiões orizícolas do sul do Brasil. Planta Daninha, v. 25, n. 1, p. 221-226, 2007a.

ANDRES, A. et al. Desempenho do cultivar de arroz BRS Pelota e controle de capim-arroz (Echinochloa spp.) submetidos a quatro épocas de entrada d'água após a aplicação de doses reduzidas de herbicidas. Planta Daninha, v. 25, n. 4, p. 859-857,2007b. 
BIANCHI, M. A.; FLECK, N. G.; LAMEGO, F. P.

Proporção entre plantas de soja e plantas competidoras e as relações de interferência mútua. Ci. Rural, v. 36, n. 5, p. 1380-1387, 2006.

CHRISTOFFOLETI, P. J.; VICTÓRIA FILHO, R. Efeitos da densidade e proporção de plantas de milho (Zea mays L.) e caruru (Amaranthus retroflexus L.) em competição. Planta Daninha, v. 14, n. 1, p. 42-47, 1996.

COMPANHIA NACIONAL DE ABASTECIMENTO CONAB. Arroz - Brasil. Série histórica de: área, produtividade e produção. Disponível em: $<\mathrm{http}$ :// www.conab.gov.br> Acesso em: 5 de jan. de 2008.

COUSENS, R. Aspects of the design and interpretation of competition (interference) experiments. Weed Technol., v. 5, n. 3, p.664-673, 1991.

COUSENS, R.; O'NEILL, M. Density dependence of replacement series experiments. Oikos, v. 66, n. 2, p. $347-$ 352, 1993.

CRALLE, H. T. et al. Wheat and Italian ryegrass (Lolium multiflorum) competition as affected by phosphorus nutrition. Weed Sci., v. 51, n. 3, p. 425-429, 2003

CROTSER, M. P.; WITT, W. W. Effect of Glycine max canopy characteristics, G. max interference, and weed-free period on Solanum ptycanthum growth. Weed Sci., v. 48, n. 1, p. $20-26,2000$.

EMPRESA BRASILEIRA DE PESQUISA AGROPECUÁRIA - EMBRAPA. Centro Nacional de Pesquisa Agropecuária de Solos (Rio de Janeiro, RJ) Sistema brasileiro de classificação de solos. Brasília: Embrapa Produção de Informação, Rio de Janeiro: Embrapa Solos, 1999. 412 p.

ESTORNINOS JR., L. E. et al. Rice and red rice interference. II. Rice response to population densities of three red rice (Oryza sativa) ecotypes. Weed Sci., v. 53, n. 5, p. 683-689, 2005.

ESTORNINOS JR., L. E.; GEALY, D. R.; TALBET, R. E. Growth response of rice (Oryza sativa) and red rice (O. sativa) in replacement series study. Weed Tecnol., v. 16, n. 2, p. 401-406, 2002.

FISCHER, A.; RAMÍREZ, H. V.; LOZANO, J. Suppression of junglerice (Echinochloa colona (L.) Link) by irrigated rice cultivars in Latin America. Agron. J., v. 89, n. 3, p. 516-521, 1997.

FLECK, N. G. et al. Interferência de plantas concorrentes em arroz irrigado modificada por métodos culturais. Planta Daninha, v. 22, n. 1, p. 19-28, 2004.
FLECK, N.G. et al. Interferência de Raphanus sativus sobre cultivares de soja durante a fase vegetativa de desenvolvimento da cultura. Planta Daninha, v. 24, n. 3, p. $425-434,2006$

FLECK, N. G. et al. Competitividade relativa entre cultivares de arroz irrigado e biótipo de arroz-vermelho. Planta Daninha, v. 26, n. 1, p. 101-111, 2008

GALON, L. et.al. Estimativa das perdas de produtividade de grãos em cultivares de arroz (Oryza sativa) pela interferência do capim-arroz (Echinochloa spp.). Planta Daninha, v. 25, n. 3, p. 697-707, 2007a.

GALON, L. et al. Níveis de dano econômico para decisão de controle de capim-arroz (Echinochloa spp.) em arroz irrigado (Oryza sativa). Planta Daninha, v. 25, n. 4, p. 709-718, $2007 b$.

GARRITY, D. P.; MOVILLON, M.; MOODY, K. Differential weed suppression ability in upland rice cultivars. Agron. J., v. 84, n. 4, p. 586-591, 1992.

GOLDBERG, D. E.; LANDA, K. Competitive effect and response: Hierarchies and correlated traits in the early stages of competition. J. Ecol., v. 79, n. 4, p. 1013-1030, 1991.

HARPER, J. L. The population biology of plants. London: Academic Press, 1977. 275 p.

HOFFMAN, M. L.; BUHLER, D. D. Utilizing Sorghum as a functional model of crop weed competition. I. Establishing a competitive hierarchy. Weed Sci., v. 50, n. 4, p. 466-472, 2002.

LAMEGO, F. P. et al. Tolerância à interferência de plantas competidoras e habilidade de supressão por genótipos de soja - II. Resposta de variáveis de produtividade. Planta Daninha, v. 22, n. 4, p. 491-498, 2004.

MALUF, A.M. Interferência interespecífica entre Amaranthus hybridus L. e Amaranthus viridis L. Pesq. Agropec. Bras., v. 34, n. 5, p. 723-732, 1999.

MELO, P. T. B. S. et al. Comportamento de populações de arroz irrigado em função das proporções de plantas originadas de sementes de alta e baixa qualidade fisiológica. R. Bras. Agroci., v. 12, n. 1, p. 37-43, 2006.

MELO, P. T. B. S. et al. Fluxo de emergência de plantas daninhas em áreas de cultivo de arroz irrigado. In: CONGRESSO BRASILEIRO DA CIÊNCIA DAS PLANTAS DANINHAS, 24., 2004, São Pedro. Anais... Londrina: Sociedade Brasileira da Ciência das Plantas Daninhas, 2004. CD-ROM. 
PANTONE, D. J.; BAKER, J. B. Reciprocal yield analysis of red rice (Oryza sativa) competition in cultivated rice Weed Sci., v. 39, n. 1, p. 42-47, 1991

PASSINI, T. Competitividade e predição de perdas de rendimento da cultura do feijão quando em convivência com Brachiaria plantaginea (Link) Hitchc. 2001. 130f. Tese (Doutorado em Agronomia) - Escola Superior de Agricultura Luiz de Queiroz, Piracicaba, 2001.

RADOSEVICH, S. R. Methods to study interactions among crops and weeds. Weed Technol., v. 1, n. 3, p. 190-189, 1987.

RIGOLI, R. P. et al. Habilidade competitiva relativa do trigo (Triticum aestivum) em convivência com azevém (Lolium multiflorum) ou nabo (Raphanus raphanistrum). Planta Daninha, v. 26, n. 1, p. 93-100, 2008

ROUSH, M. L. et al. A comparison of methods for measuring effects of density and proportion in plant competition experiments. Weed Sci., v. 37, n. 2, p. 268-275, 1989.
RUIZ-SANTELLA, J. P.; FISCHER, A. J.; PRADO, R. Alternative control of two biotypes of Echinochloa phyllopogon susceptible and resistant to fenoxaprop-ethyl. Comm. Agric. Appl. Biol. Sci., v. 68, n. 4, p. 403-407, 2003.

SAS Institute. Statistical Analysis System. User's guide. 4.ed. Cary: 1989. 846 p.

SOCIEDADE SUL-BRASILEIRA DE ARROZ IRRIGADO - SOSBAI. Arroz irrigado: Recomendações técnicas da pesquisa para o Sul do Brasil. Santa Maria: Universidade Federal de Santa Maria, 2005. 159 p

VIDA, F. B. P. et al. Relating rice traits to weed competitiveness and yield: A path analysis. Weed Sci., v. 54, n. 6 , p. $1122-1131,2006$.

VILÁ, M. et al. Competition experiments on alien weeds with crops: Lessons for measuring plant invasion impact? Biol. Invas., v. 6, n. 1, p. 59-69, 2004. 